\title{
ENHANCEMENT OF SKIN PERMEABILITY OF ECONAZOLE NITRATE USING NOVEL FLEXISOMAL NANOCARRIERS BY IMPLEMENTING QUALITY BY DESIGN (QBD) APPROACH
}

\author{
SATISH K. MANDLIK*, HARSHAL P. DANDGAVHAL \\ STES's Sinhgad College of Pharmacy Vadgaon (Bk), SP Pune University, Pune, India \\ Email: satish4004@gmail.com
}

Received: 28 Aug 2019, Revised and Accepted: 12 Nov 2019

\section{ABSTRACT}

Objective: The purpose of this study was an implementation of quality by design (QbD) for the formulation and characterization of econazole nitrate loaded flexisomal nanocarriers (EN-FS) to improve antifungal activity and to enhance skin permeability.

Methods: Initially quality target product profile (QTTP) elements were identified and later critical quality attributes (CQA) elements were defined from QTPP elements. Particle size, entrapment efficiency and deformability index were defined as CQAs. Risk assessment was performed by using fishbone diagram and failure mode and effect analysis (FMEA). Design space was created by using fractional factorial design $2^{5-2}$ as screening design and $3^{2}$ full factorial design as optimization design to optimize two variables soya phosphatidylcholine concentration $\left(\mathrm{X}_{1}\right)$ and sodium deoxycholate concentration $\left(\mathrm{X}_{2}\right)$.

Results: Optimized batch of EN-FS was $249.5 \pm 3.48 \mathrm{~nm}$, with entrapment efficiency of $88.6 \pm 0.89 \%$ and deformability index of $31.75 \pm 0.98$. Zeta potential analysis showed value of-22.5 mV. Morphological analysis by TEM showed spherical shaped flexisomes, which confirmed the vesicular characteristics. The optimized batch of EN-FS was further made into hydrogels by using sepineo P600 as gelling agent. The \% drug diffusion of ENFS hydrogels had shown $24.68 \%$. With higher skin deposition and higher value of zone of inhibition in antifungal study as compared to plain EN hydrogel. CLSM studies indicated deep penetration of EN-FS in skin layers. Lastly control strategy for EN-FS were developed.

Conclusion: It was concluded that EN-FS showed high flexibility and enhanced antifungal activity therefore found to be a potential nanocarriers for drug deposition in skin layers without disturbing skin integrity.

Keywords: Quality by design, Econazole nitrate, Flexisomes, Antifungal, Optimization

(C) 2020 The Authors. Published by Innovare Academic Sciences Pvt Ltd. This is an open access article under the CC BY license (http://creativecommons.org/licenses/by/4.0/) DOI: http://dx.doi.org/10.22159/ijap.2020v12i1.35499. Journal homepage: https://innovareacademics.in/journals/index.php/ijap

\section{INTRODUCTION}

Quality by design (QbD) ensures that 'quality should be built into product rather than tested in product' as stated by quality expert Joseph M. Juran [1]. According to ICH Q8 R2 guidelines QbD is defined as "A systematic approach to development that begins with predefined objectives and emphasizes product and process understanding and process control, based on sound science and quality risk management" [2]. QbD made up of three ICH guidelines i.e. ICH Q8, Q9 and Q10 namely pharmaceutical development, quality risk management and pharmaceutical quality systems respectively. QbD has mainly four important elements (i) To identify quality target product profile (QTPP) based on prior knowledge. (ii)To define critical quality attributes (CQA's), critical material attributes (CMA's) and critical process parameters (CPP's). (iii)To perform risk assessment by various tools such as ishikawa diagram (fishbone diagram) and failure mode effect analysis (FMEA). (iv) To establish design space and to define the control strategy. Three important tools of the $\mathrm{QbD}$ are design of experiments (DoE), process analytical technology (PAT) and risk management [3-6].

Flexisomes are self-aggregating, deformable, flexible, stressresponsive lipidic vesicle, its preferred form is an ultra-deformable vesicle which possess an aqueous core surrounded by the complex lipid bilayer. It carries both hydrophilic and hydrophobic properties. Flexisomes are referred as first generation of the elastic vesicles which made up of phospholipids and edge activator, Mandlik et al. [7]. Phospholipids which are used in preparation are soya phosphatidylcholine, egg phosphatidylcholine, dipalmitoyl phosphatidylcholine, distearoyl phosphatidylcholine. Various edge activators used in preparation of flexisomes are sodium cholate, sodium deoxycholate, span 80 , and tween 80 which are single-chain surfactant that destabilizes the lipid membrane thus produce high flexibility, this flexibility leads to better permeation through pores of skin membrane [8-10]. Flexisomes overcome the skin penetration difficulty by squeezing themselves along the intracellular sealing lipid because of high vesicular flexibility, which permits entry in deeper layers of skin due to the mechanical stress of surrounding in a self-adapting manner. They can deform up to 3 to 4 times of their own diameter, and regain its shape, Cevc et al., Patidar et al. [11,12].

Skin is the largest organ of the human body and fungal skin infections are affecting over 50 million people all over the world especially in developing and underdeveloped nations, Gungor et al. [13]. Various imidazole derivatives have been used to treat topical fungal infections such as fluconazole, ketoconazole, clotrimazole, voriconazole, oxiconazole nitrate and miconazole nitrate. Econazole nitrate (EN) (1[2-(4-chlorophenyl) methoxy]-2-(2, 4-dichlorophenyl) ethyl)-1Himidazole mononitrate is a broad-spectrum imidazole antifungal drug mainly used to treat skin infections such as candidiasis, Keshri et al. [14]. EN belongs to the BCS class (IV) so it has both rate-limited release and permeability. EN blocks the ergesterol synthesis thus it prevents leads to prevention of fungal cell multiplication. EN commercially available as $1 \%$ cream and $1 \%$ liposomal gel. Flexisomes have been designed to overcome the problem of release and permeability, Sharma et al. [15].

In this research work, EN loaded flexisomal nanocarriers (EN-FS) were prepared by thin-film hydration method to improve skin permeability and antifungal activity by implementing $\mathrm{QbD}$ approach.

\section{MATERIALS AND METHODS}

\section{Materials}

Materials used in this experiment were of AR/IR grade. Phospholipid used for vesicle formation was Lipoid S75 containing 70\% phosphatidylcholine i.e. soya phosphatidylcholine (SPC) was obtained from Lipoid GmbH (Ludwigshafen, Germany). EN was purchased from Yarrow chemicals (Mumbai, India). Sodium deoxycholate (SDC) was obtained from Loba Chemicals Pvt. Ltd. (Mumbai, India) which was used as edge activator. Chloroform obtained from Loba Chemicals Pvt. Ltd. (Mumbai, India), Methanol was obtained from Merck India Ltd. (Mumbai, India). Disodium hydrogen phosphate and Potassium dihydrogen phosphate were 
obtained from Loba Chemicals Pvt. Ltd. (Mumbai, India) and Sepineo P600 as a gelling agent was obtained from Air Liquide (Mumbai, India).

\section{Methods}

\section{Identification of quality target product profile (QTPP) elements}

QTTP is a prospective summary of the quality characteristics of a EN-FS that ideally will be achieved to ensure the desired quality, taking into account safety and efficacy by patient's point of view of the EN-FS. Based on the clinical and pharmacokinetic characteristics, preformulation studies and extensive literature survey QTPP elements for EN-FS were identified [3, 16, 17].

\section{Determination of critical quality attributes (CQA)}

A CQA is defined as 'any physical, chemical, biological property or characteristic that should be within an appropriate limit, range, or distribution to ensure the desired product quality'. CQA are generally associated with the drug substance, excipients, intermediates (in-process materials) and drug product. Based on prior knowledge, sound science CQA were defined from QTPP elements $[3,18]$.

\section{Assessment of risk (RA)}

Initial RA was performed by using two tools as Ishikawa diagram (fish bone diagram) and failure mode and effect analysis (FMEA). Fish-bone diagram was considered as primary tool to identify the potential risks factor of formulation and development of flexisomes which could affects desired CQA. Based on prior knowledge FMEA method were further applied in the initial risk analysis of the parameters of the flexisomes [19], Each variable was evaluated in terms of severity (S), detectability (D) and probability (P). Severity is the how severely will be the variable affects to the final product. Detectability defined that a failure mode can be detected. The final parameter probability is considered as the occurrence probability or the likelihood of a failure. For each risk, S, D, P scores in the range of 1 to 3 (low to high risk) were given and multiplied ( $\mathrm{S} \times \mathrm{D} \times \mathrm{P}$ ) to produce a "Risk Priority Number" (RPN). The RPN threshold was set at 15; any process parameter with an RPN 15 or above was regarded as a potential critical factor which impact on CQAs and in product safety and efficacy, while factors with a lower RPN can be eliminated from further study already stated by Nasr et al. [5, 20].

\section{Establishment of design space (DS)}

Design space is the multidimensional combination and interaction of critical material attributes and process parameters that have been demonstrated to provide assurance of quality [19]. Design space was established by using design of experiment (DoE) tool. In DoE, $2^{5-2}$ fractional factorial design as a screening design and $3^{2}$ full factorial design as a main optimization design were implemented [22, 23].

\section{Preparation of EN-FS}

The EN-FS were prepared by modified thin film hydration method by using rotary evaporator and probe sonication [24]. Lipoid S75 (SPC) as vesicle forming lipid, Sodium deoxycholate (SDC) as edge activator and EN were added to a round bottom flask and all the contents were dissolved in organic solvents (Methanol: Chloroform, 1:1). The resulting mixture was set for rotary evaporation $\left(60{ }^{\circ} \mathrm{C}\right.$ for $1 \mathrm{~h}$ ) to form a thin lipidic film. The deposited lipidic thin film was hydrated by gentle shaking with $10 \mathrm{ml}$ phosphate buffer solution of $\mathrm{pH}$ 7.4. The resulting vesicles were set aside to swallow for 2 to $3 \mathrm{~h}$ at room temperature to get large multi lamellar vesicles $[7,25]$. Further size reduction of vesicles was obtained by probe sonication.

\section{Fractional factorial design as screening design (25-2)}

Based on risk assessment results, identified critical parameters

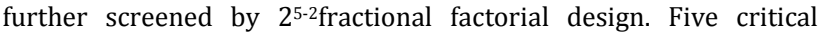
parameters (CPP and CMA) each varied with two levels were SPC concentration, $X_{1}$ (250-500 mg), SDC concentration. $X_{2}$ (100-150 $\mathrm{mg})$, probe sonication time, $\mathrm{X}_{3}(2-4 \mathrm{~min})$, Speed of the rotary evaporator, $\mathrm{X}_{4}(160-220 \mathrm{rpm})$ and hydration medium $\mathrm{pH}, \mathrm{X}_{5}(6.8-$ 7.4) selected which may affect CQAs. As per screening design 8 batches of flexisomes were prepared and evaluated.

\section{$3^{2}$ full factorial design as optimization design}

After screening design 2 supercritical parameters were selected and their effect on CQAs were optimized by $3^{2}$ factorial design. Two super critical parameters each varied with three levels were SPC concentration, $X_{1}(250-500-750 \mathrm{mg})$ and SDC concentration, $X_{2 .}(50-$ $100-150 \mathrm{mg}$ ) were varied at three levels as high [+1], medium [0] and low [-1]. The predefined CQA's were particle size $\left(\mathrm{Y}_{1}\right)$, entrapment efficiency $\left(\mathrm{Y}_{2}\right)$ and deformability index $\left(\mathrm{Y}_{3}\right)$.

\section{Evaluation of the prepared flexisomes}

Particle size determination (PS): mean particle size of EN-FS was measured by differential light scattering (DLS) by using particle size analyzer (Horiba SZ100, Japan) instrument. Polydispersity index was also determined to measure uniformity of particle diameter and it shows size distribution of the flexisomes.

Entrapment efficiency (EE): Entrapment efficiency was determined by conventional method of centrifugation. Flexisomes suspension was placed in centrifuge tube for $30 \mathrm{~min}$ at $15000 \mathrm{rpm}$. Supernatant was withdrawn and further diluted with suitable solvent i.e. phosphate buffer solution of $\mathrm{pH}$ 7.4. EE was calculated by the formula [25]

$$
\% \text { Entrapment Efficiency }=\frac{\text { (Total Drug-Unentrapped drug) }}{\text { Total Drug }} \times 100
$$

Deformability index (DI): the elasticity of flexisomal vesicles were measured by extrusion method by membrane filtration. Deformability index is the measure of how elastic is the vesicle. Flexisomes were extruded through filter membrane (pore size diameter $100 \mathrm{~nm}$ ) using a stainless steel filter holder, by applying 2 bar pressure. Flexisomes were extruded for $5 \mathrm{~min}$ and quantity of suspension were measured. Deformability index was measured by formula [26-28].

$$
\mathrm{DI}=\mathrm{J} \times\left(\frac{\mathrm{r}_{\mathrm{v}}}{\mathrm{r}_{\mathrm{p}}}\right)^{2}
$$

$\mathrm{DI}=$ Deformability Index

$\mathrm{r}_{\mathrm{v}}=$ Vesicles size, $\mathrm{rp}=$ pore diameter

and $\mathrm{J}=$ suspension amount extruded in $5 \mathrm{~min}$,

\section{Statistical analysis and regression analysis}

Statistical analysis of the design was carried out by using licensed Design Expert V-8 software (Stat Ease Inc. MN, USA). The obtained data were fitted in the Design Expert Software to analyze different statistical parameters. The regression analysis was expressed using polynomial equation (3), ANOVA, response surface plot (3-D graphs) and contour plots (2-D graphs) $[29,30]$.

$$
Y=\beta_{0}+\beta_{1} X_{1}+\beta_{2} X_{2}+\beta_{3} X_{1} X_{2}+\beta_{4} X_{1}^{2}+\beta_{5} X_{2}^{2}
$$

\section{Selection of optimized batch}

Optimum formulation was selected by the critical evaluation from desirability factors. The criteria for selection of optimum preparations were primarily based on the highest possible values of, deformability index (DI), drug entrapment efficiency (\%) and optimum value in range of (200 to $300 \mathrm{~nm}$ ) of particle size i.e. 3 to 4 times more than that of skin pore size, so flexisomes can squeeze themselves up to 3 to 4 times and can penetrate through narrow skin pores [7].

\section{Evaluation of optimized batch}

Zeta potential measurements (surface charge study): sample firstly diluted with double distilled water and measurements were done in dip cell by differential light scattering (DLS) using instrument (Horiba SZ-100). The stability of vesicular suspension is directly related to the magnitude of the surface charge. Zeta potential value indicated stability of dispersion.

Surface morphology study by transmission electron microscope (TEM): surface morphology study of optimized batch of flexisomes was carried out by transmission electron microscope (Phillips CM 200, Netherland). Morphological structure and size were analyzed 
by TEM. Flexisomal sample before extrusion and after extrusion through filter membrane were both analyzed under TEM [31].

\section{Preparation of flexisomal loaded sepineo ge}

Sepineo P600 (Acrylamide/Sodium Acryloyldimethyl Taurate Copolymer/Isohexadecane and Polysorbate 80) was used as gelling agent in concentration range of $3 \%$ and $5 \% \mathrm{w} / \mathrm{w}$ [32]. Sepineo P600 was added in flexisomal suspension in concentration range of $3 \%$ and 5\%. Methyl and propyl paraben was added as preservative. Gel of good consistency and of $\mathrm{pH} 6$ to 7 was prepared. Gel was evaluated by various parameters such as appearance, spreadability, viscosity, drug content, gel $\mathrm{pH}$ [33].

\section{Spreadability}

The spreadability was measured by placing 0.5 gm gel sample within a circle of $1 \mathrm{~cm}$ diameter marked on a glass plate over which a second glass plate was placed. A weight of $0.5 \mathrm{~kg}$ was put on the upper glass plate for $5 \mathrm{~min}$. The increase in the diameter due to spreading of gel sample was noted $[35,37]$.

\section{Viscosity}

The viscosity of flexisomal gel were carried out on Brook-field viscometer. The sample (50 gm) was placed in a beaker and allowed to equilibrate for $5 \mathrm{~min}$. before measuring the dial reading using T-B spindle at $0.5,1,2.5$, and $5 \mathrm{rpm}$. At each speed, dial reading on the viscometer was noted. Direct multiplication of the dial readings with factors given in the Brookfield viscometer catalogue gave the viscosity in centipoises [34-37].

\section{Drug content}

Drug content was determined by taking $1 \mathrm{~g}$ of flexisomal gel (equivalent to $1 \%$ of the drug) in $10 \mathrm{ml}$ volumetric flask. From this solution, $1 \mathrm{ml}$ was withdrawn and volume adjusted to $10 \mathrm{ml}$ with methanol. The absorbance was taken at a $\lambda_{\max } 264 \mathrm{~nm}$ by UVSpectrophotometer [35-37].

\section{Ex vivo drug diffusion studies}

The drug diffusion studies were carried out using Franz-type diffusion cell on skin of human cadaver. Skin had taken from the abdominal region. Franz diffusion cell having effective diffusion area of $2.6 \mathrm{~cm}^{2}$ was used for ex vivo drug diffusion studies of EN-FSs gel and compared with plain EN gel. Donor compartment which consists of EN-FSs gel at maintained temperature of $37 \pm 0.5{ }^{\circ} \mathrm{C}$ and sink condition was maintained. At set intervals of 1 to $7 \mathrm{~h}$, sample of the receiver medium was withdrawn at the predetermined time and replaced immediately with an equal volume of fresh buffer solution of $\mathrm{pH}$ 7.4. UV-Visible spectrophotometer was used to analyze samples. The amount of EN permeated through human cadaver skin was plotted vs time [34, 35].

\section{Drug deposition studies on human cadaver skin}

The drug deposited in the human cadaver skin was determined by drug deposition studies after diffusion study diffusion cell the after a period of $7 \mathrm{~h}$ and the skin was removed. Gel was wiped off from surface of skin.
Skin cut into small pieces further homogenized and the drug present in the skin was extracted with $50 \mathrm{ml}$ methanol by means of sonication, after $24 \mathrm{~h}$ filtered through $0.45 \mathrm{~mm}$ membrane filter and then analyzed with help of UV-visible spectrophotometer at wavelength $264 \mathrm{~nm}$ in suitable dilutions [7, 36, 37].

\section{Histopathological study}

Histopathological examination of skin sample after diffusion was carried out and compared with piece of fresh excised untreated skin sample as a control. The skin was kept in $10 \%$ formalin for period of $24 \mathrm{~h}$ and then transverse section had taken ( $4 \mathrm{~mm}$ width). Each section was dehydrated by using ethanol and then embedded in paraffin wax. Transverse section was stained with hematoxylin and eosin and then observed under microscope in sufficient resolution [36, 38].

\section{Confocal laser scanning microscopy (CLSM)}

Depth and mechanism of skin permeation of rhodamine red-loaded flexisomes was investigated using CLSM study. Rhodamine-red loaded flexisomal suspension was prepared with rhodamine red, soya lecithin (SPC) and sodium deoxycholate (SDC). Rhodamine red loaded flexisomes were prepared by conventional rotary evaporation sonication method. The formulation (i.e., containing vesicles was applied nonocclusively to the abdominal section of human cadaver skin. The skin sample was sliced in sections of 10-15 $\mu \mathrm{m}$ in thickness through the z-axis and examined with confocal laser scanning microscopy (NIKON A1R; Tokyo, Japan). Optical excitations were carried out with a 488-nm argon laser beam, and fluorescence emission was detected above $560 \mathrm{~nm}$ for rhodamine red $[38,40]$.

\section{In vitro antifungal activity}

The antifungal activity was determined against Candida albicans (ATCC 2091) species by cup plate method. The diameter of zone of inhibition was measured as an antifungal efficacy of plain gel and econazole nitrate loaded flexisomal gel. A sterilized sabouraud dextrose agar media was poured into sterilized petri plates; all conditions were taking place in an aseptic area. Suspension of Candida albicans culture was spread uniformly on the solidified sabouraud dextrose agar. The cups were cut and formulations were filled in laminar airflow by sterilized syringe. Plates were covered with lids and further incubated at $32{ }^{\circ} \mathrm{C}$ for $40 \mathrm{~h}$. The zones of inhibition were measured. Aseptic condition was maintained during study $[38,40]$.

\section{RESULTS AND DISCUSSION}

\section{Identification of QTPP}

Based on scientific prior knowledge, a thorough literature survey and preliminary studies QTPP elements for the EN-FS were identified and are shown in table 1.

\section{Determination of CQA}

Based on scientific prior knowledge and preliminary studies three CQA were defined from QTPP elements as particle size, entrapment efficiency and deformability index. CQA and their justification is shown in table 2 .

Table 1: QTPP elements for econazole nitrate loaded flexisomes

\begin{tabular}{lll}
\hline QTPP elements & Target & Justification \\
\hline Formulation & Flexisomes & For better skin permeability \\
$\begin{array}{l}\text { Dosage form } \\
\text { Route of administration }\end{array}$ & Gel & For better skin permeability. \\
Stability & At least 24 mo shelf life at room temp. & Pharmaceutical equivalence requirement: Same route of administration \\
Drug product quality & Physical attributes & Equivent to or better than marketed preparation shelf-life \\
attributes & Identification & Pharmaceutical equivalence requirement: Meeting the same compendial or \\
& Entrapment efficiency & other applicable (quality) standards (i.e., identity, assay, purity, and \\
& Particle size & quality) \\
& Deformability index & \\
& Drug release & \\
& Drug loading & \\
& Suitable container closure system to & Selected based on similarity to the marketed preparation packaging. No \\
Container closure system & achieved target shelf life & \\
& &
\end{tabular}




\section{Assessment of risk}

Initial risk assessment was done by using ishikawa diagram (fishbone diagram) several critical parameters were obtained by ishikawa diagram which may affects CQA's so as formulation which was preformed according to ICH Q8 R2, to identify a CPP and CMA of CQAs that affects the quality of flexisomes shown in fig. 1 (a). According to $5 \mathrm{M}$ concept, we had systematically gathered up all the possible factors in fishbone diagram that could influence flexisomal product quality, on the basis of literature data, various previous study experiences and preformulation data.

Table 2: CQA elements for econazole nitrate loaded flexisomes

\begin{tabular}{|c|c|c|}
\hline CQAs & Target & Justification \\
\hline Particle Size & $\begin{array}{l}\text { Should be minimum (In range of } \\
200 \text { to } 300 \mathrm{~nm} \text { ) Larger than } \\
\text { diameter of skin pores }\end{array}$ & $\begin{array}{l}\text { Particle size will affect the penetration through the skin. So as the effectiveness of the } \\
\text { formulation. If particle size is larger than skin pores then flexisomes can squeeze themselves } \\
\text { up to } 3 \text { to } 4 \text { times of their own diameter and can pass through narrow skin pores }\end{array}$ \\
\hline $\begin{array}{l}\text { Entrapment } \\
\text { Efficiency }\end{array}$ & Should be maximum & $\begin{array}{l}\text { It will affect Drug release from the formulation. If more amount of drug gets entrapped in } \\
\text { vesicle more drug will be present at the site of action }\end{array}$ \\
\hline $\begin{array}{l}\text { Deformability } \\
\text { Index }\end{array}$ & Should be maximum & Deformability index will affect the flexibility and also penetration through skin pores. \\
\hline
\end{tabular}

By RPN score of FMEA which was based on prior knowledge and preliminary study, each variable was scored on Severity, Detectability and Probability of risk by fishbone factors. Five highrisk factors which affects CQA was studied by FMEA and the score of RPN was above 15 (RPN>15) which were identified as critical factors in manufacturing the flexisomes shown in fig. 1 (b). Five parameters selected were 1. SPC concentration, 2. SDC concentration, 3. Probe sonication time, 4. Hydration medium $\mathrm{pH}$ and 5. Speed of rotary evaporator (RPM) as critical parameter which can severely affect the flexisomes, by taking this 5 parameters, design space was created and further used in fractional factorial design as a screening design.

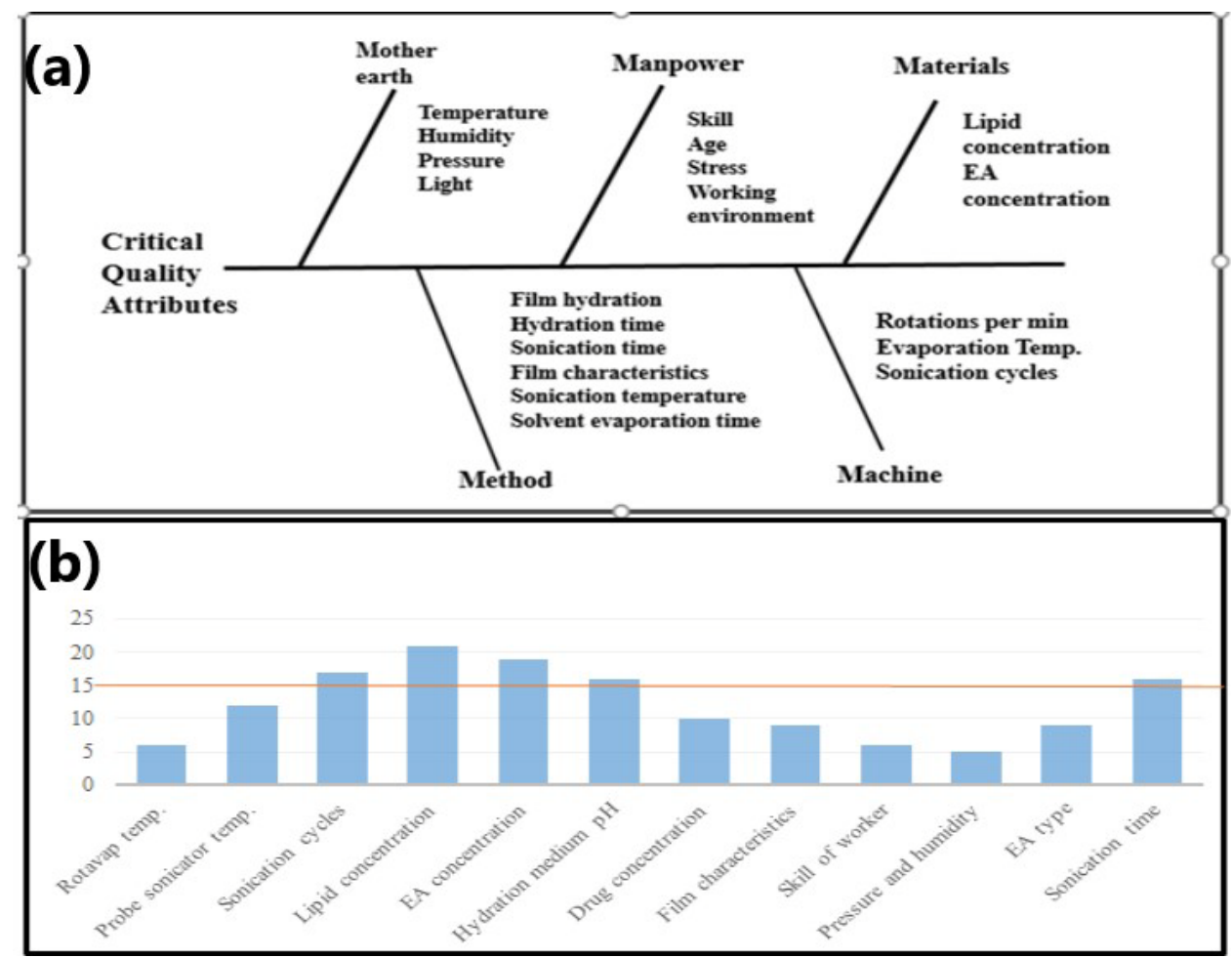

Fig. 1: (a): Fish-bone diagram illustrating factors that may have an impact on particle size, entrapment efficiency and deformability index (CQAs). (b): Risk priority number (RPN) score after failure mode and effect analysis risk assessments any variable above the RPN threshold of 15 was consider as a potential risk factors

\section{Establishment of design space}

A design of experiments (DoE) is an experimental tool was used to establish design space. In screening design, a $2^{5-2}$ fractional factorial design was implemented with 8 runs, whereas $3^{2}$ full factorial design with 9 runs was used as main optimization design.

\section{Screening of factors by $2^{5-2}$ as screening design}

The results obtained from $2^{5-2}$ fractional factorial design were, particle size was found in range from $185.3 \pm 2.01 \mathrm{~nm}$ to $290.22 \pm 3.20 \mathrm{~nm}$ and entrapment efficiency in range from $70.3 \pm 2.14 \%$ to $81.8 \pm 1.89 \%$. as shown in table 3. From screening design, it was seen that SPC concentration and SDC concentration significantly affected results of particle size and entrapment efficiency, as the effect of various independent variables in screening design is shown in pare to charts by means of $t$ value effect in fig. 2. From pare to chart it was determined that two independent variables i.e. 1. SPC concentration (lipid conc.) and 2. SDC concentration (edge activator concentration) dominantly impacts particle size and entrapment efficiency.

So that for optimization study, other three factors were excluded, and further study continued with SPC concentration and SDC concentration. 
Table 3: Design matrix for fractional factorial design $\left(2^{5-2}\right)$ (Screening design)

\begin{tabular}{|c|c|c|c|c|c|c|c|}
\hline \multirow[t]{2}{*}{ Std } & \multicolumn{5}{|c|}{ Independent variables } & \multicolumn{2}{|c|}{ Dependent variables } \\
\hline & $\begin{array}{l}\text { SPC conc. } \\
\left(X_{1}\right)\end{array}$ & $\begin{array}{l}\text { SDC conc. } \\
\left(X_{2}\right)\end{array}$ & $\begin{array}{l}\text { Sonication } \\
\text { time }\left(X_{3}\right)\end{array}$ & $\begin{array}{l}\text { Speed of rotavap } \\
\left(\mathrm{X}_{4}\right)\end{array}$ & $\begin{array}{l}\text { Hydration medium } \\
\text { pH }\left(X_{5}\right)\end{array}$ & $\begin{array}{l}\text { Particle } \\
\text { size }\left(Y_{1}\right)\end{array}$ & $\begin{array}{l}\text { Entrapment efficiency } \\
\left(\mathrm{Y}_{2}\right)\end{array}$ \\
\hline 1 & $250 \mathrm{mg}$ & $100 \mathrm{mg}$ & $2 \mathrm{~min}$ & 220rpm & 7.4 & $185.3 \pm 2.01$ & $73.3 \pm 3.45$ \\
\hline 2 & $500 \mathrm{mg}$ & $100 \mathrm{mg}$ & $2 \mathrm{~min}$ & 160rpm & 6.8 & $230.1 \pm 1.52$ & $77.4 \pm 2.51$ \\
\hline 3 & $250 \mathrm{mg}$ & $150 \mathrm{mg}$ & $2 \mathrm{~min}$ & 160rpm & 7.4 & $198.8 \pm 1.56$ & $70.8 \pm 3.50$ \\
\hline 4 & $500 \mathrm{mg}$ & $150 \mathrm{mg}$ & $2 \mathrm{~min}$ & 220rpm & 6.8 & $258.3 \pm 3.01$ & $74.6 \pm 1.56$ \\
\hline 5 & $250 \mathrm{mg}$ & $100 \mathrm{mg}$ & $4 \mathrm{~min}$ & 220rpm & 6.8 & $182.5 \pm 1.4$ & $70.3 \pm 2.14$ \\
\hline 6 & $500 \mathrm{mg}$ & $100 \mathrm{mg}$ & $4 \mathrm{~min}$ & 160rpm & 7.4 & $231.4 \pm 2.10$ & $81.8 \pm 1.89$ \\
\hline 7 & $250 \mathrm{mg}$ & $150 \mathrm{mg}$ & $4 \mathrm{~min}$ & 160rpm & 6.8 & $192.2 \pm 1.35$ & $74.3 \pm 3.01$ \\
\hline 8 & $500 \mathrm{mg}$ & $150 \mathrm{mg}$ & $4 \mathrm{~min}$ & 220rpm & 7.4 & $290.2 \pm 3.20$ & $79.2 \pm 2.87$ \\
\hline
\end{tabular}

SPC: Soya phosphatidylcholine, SDC: Sodium deoxycholate, Data are presented as mean \pm SD $(n=3)$

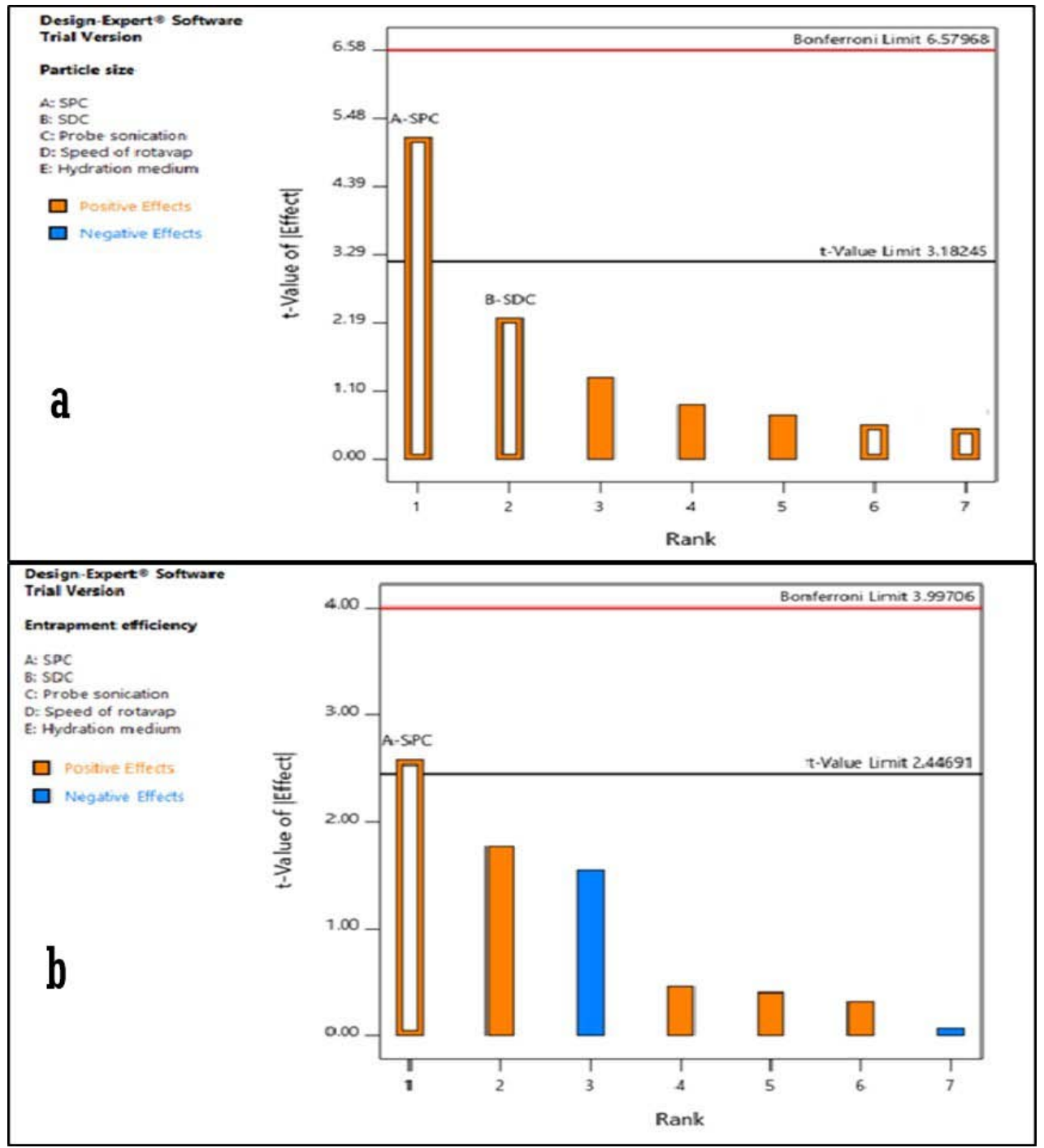

Fig. 2: Pareto charts showing the effects of independent variables on (a) Particle size and (b) Entrapment efficiency. Soya phosphatidylcholine (SPC), Sodium deoxycholate (SDC)

\section{Optimization by $3^{2}$ full factorial design}

9 batches were prepared with two independent variables as 1. SPC concentration and 2. SDC concentration which was evaluated at three levels with response variables as particle size (PS), entrapment efficiency (EE) and deformability index (DI). Results for 9 batches are shown in table 4. R1 shows smallest particle size $175.4 \pm 4.62$ where $\mathrm{R} 9$ shows highest particle size as $614.5 \pm 4.68$ showed that particle size increases with increase in SPC concentration. The polydispersity index of all batches was found in range of 0.1 to 0 . 4 . Batch R1 shows smallest EE where R5 shows highest EE. Deformability index is an important property of flexisomes which states flexibility of the flexisomes. DI was done by extrusion method using assembly of membrane filtration. DI of all batches were in range of $16.21 \pm 0.15$ to $31.75 \pm 0.98$. R1 batch shows minimum DI where R5 shows maximum. It was found that DI increases as the concentration of edge activator increases as it destabilizes lipid bilayer to make it more flexible. 
Table 4: $\mathbf{3}^{2}$ full factorial design with corresponding 9 formulations

\begin{tabular}{lllll}
\hline Run & $\begin{array}{l}\text { SPC conc. } \\
\left(\mathbf{X}_{\mathbf{1}}\right)\end{array}$ & $\begin{array}{l}\text { SDC conc. } \\
\left(\mathbf{X}_{\mathbf{2}}\right)\end{array}$ & $\begin{array}{l}\text { Particle size } \\
\left(\mathbf{Y}_{\mathbf{1}}\right)\end{array}$ & $\begin{array}{l}\text { Entrapment efficiency } \\
\left(\mathbf{Y}_{\mathbf{2}}\right)\end{array}$ \\
\hline $\mathrm{R}_{1}$ & $250 \mathrm{mg}$ & $50 \mathrm{mg}$ & $175.4 \pm 4.62$ & $72.6 \pm 0.66$ \\
$\mathrm{R}_{2}$ & $500 \mathrm{mg}$ & $50 \mathrm{mg}$ & $187.7 \pm 3.65$ & $86.4 \pm 1.21$ \\
$\mathrm{R}_{3}$ & $750 \mathrm{mg}$ & $50 \mathrm{mg}$ & $279.9 \pm 6.14$ & $87.4 \pm 0.36$ \\
$\mathrm{R}_{4}$ & $250 \mathrm{mg}$ & $100 \mathrm{mg}$ & $237.3 \pm 5.13$ & $74.3 \pm 0.28$ \\
$\mathrm{R}_{5}$ & $500 \mathrm{mg}$ & $100 \mathrm{mg}$ & $249.5 \pm 3.48$ & $88.7 \pm 0.89$ \\
$\mathrm{R}_{6}$ & $750 \mathrm{mg}$ & $100 \mathrm{mg}$ & $350.9 \pm 5.24$ & $79.4 \pm 1.53$ \\
$\mathrm{R}_{7}$ & $250 \mathrm{mg}$ & $150 \mathrm{mg}$ & $156.3 \pm 3.65$ & $69.79 \pm 0.68$ \\
$\mathrm{R}_{8}$ & $500 \mathrm{mg}$ & $150 \mathrm{mg}$ & $301.2 \pm 2.13$ & $80.6 \pm 0.91$ \\
$\mathrm{R}_{9}$ & $750 \mathrm{mg}$ & $150 \mathrm{mg}$ & $614.5 \pm 4.68$ & $75.5 \pm 0.16$ \\
\hline
\end{tabular}

SPC: Soya phosphatidylcholine, SDC: Sodium deoxycholate, Data are presented as mean $\pm S D(n=3)$

\section{Statistical analysis}

\section{Statistical model analysis for particle size $\left(\mathrm{Y}_{1}\right)$}

2FI model was found to be an adequate model for the particle size, $2 \mathrm{FI}$ equation is shown as

$$
\mathrm{Y}_{1}(\mathrm{PS})=283.63+112.72 \mathrm{X}_{1+}+71.50 \mathrm{X}_{2+} 88.42 \mathrm{X}_{1} \mathrm{X}_{2}(1)
$$

From above polynomial, it was found that particle size increases with increase in SPC concentration $\left(\mathrm{X}_{1}\right)$ concentration also particle size increases with increase in $\operatorname{SDC}$ concentration $\left(\mathrm{X}_{2}\right)$. Also interaction of both factors results in increases in particle size up to certain concentrations. In which SPC concentration significantly affects the particle size as compared to SDC concentration. Analysis of variance (ANOVA) was performed. It was found that the p-value is 0.0074 which is less than 0.05 which indicates model terms were significant.

\section{Graphical representation}

Response surface plot in fig. 3 (a) shows that particle size increases either increase in SPC concentration or SDC concentration also interaction of both factors results in an increase in particle size as mentioned in polynomial equation. Effects of different proportion of various independent variables is shown in contour plot fig. 3 (b).

\section{Regression model analysis for entrapment efficiency $[\mathrm{EE}]\left(\mathrm{Y}_{2}\right)$}

Quadratic model was found to be an adequate model for the entrapment efficiency; quadratic equation is shown as,

$$
\mathrm{Y}_{2}(\mathrm{EE})=86.62+4.27 \mathrm{X}_{1}-3.42 \mathrm{X}_{2}-2.27 \mathrm{X}_{1} \mathrm{X}_{2}-8.73 \mathrm{X}_{1}^{2}-2.09 \mathrm{X}_{2}^{2}(2)
$$

The above polynomial equation shows that SPC concentration $\left(\mathrm{X}_{1}\right)$ has positive signs so that entrapment efficiency increases with increase in SPC (Lipid) concentration. In above equation $\mathrm{X}_{2}$ has negative coefficient which shows an increase in concentration of SDC (Edge activator) results in decrease in entrapment efficiency, although entrapment efficiency increases with increase in concentration of SDC up to certain limit above which there is decrease in entrapment efficiency. Also interaction of both factors shows negative coefficient which indicates decrease in entrapment efficiency. From quadratic equation it was found that $\mathrm{X}_{1}$ significantly affects the entrapment efficiency. Analysis of variance (ANOVA) was performed. It was found that $\mathrm{p}$-value was 0.0372 which was less than 0.05 which indicates model terms were significant [41].

\section{Graphical representation}

Response surface plot and contour plot is shown in fig. 3(c) and fig. 3 (d) respectively. Response surface plot shows that on an increase of concentration of $\mathrm{X}_{1}$, entrapment efficiency significantly increases. $\mathrm{X}_{2}$ shows negative effect on entrapment efficiency. Interaction of both factors results in slightly increase in entrapment efficiency, further increase in concentration results in decrease in entrapment efficiency as shown in polynomial equation.

\section{Regression model analysis for Deformability index (DI) [ $\left.\mathrm{Y}_{3}\right]$}

Quadratic model was found to be adequate model for the deformability index, the quadratic equation is shown as

\section{$\mathrm{Y}_{3}(\mathrm{DI})=31.07+0.1866 \mathrm{X}_{1+2}+46 \mathrm{X}_{2}-0.8850 \mathrm{X}_{1} \mathrm{X}_{2}-1.31 \mathrm{X}_{1}^{2}-10.56 \mathrm{X}_{2}{ }^{2}$ (3)}

Above polynomial equation shows that both $\mathrm{X}_{1}$ and $\mathrm{X}_{2}$ bears positive coefficients. It shows that the deformability index increases with increase in both lipid (SPC) and surfactant (SDC) concentration but deformability index significantly increases with increase in concentration of surfactant $\left(\mathrm{X}_{2}\right)$. Also interaction of both factors shows negative coefficient which indicates decrease in deformability index, although up to critical concentration interaction of both factors favors the deformability index. Analysis of variance (ANOVA) was performed. It was found that $\mathrm{p}$-value 0.0037 which is less than 0.05 which indicates model terms were significant.

\section{Graphical representation}

Response surface plot and contour plot is shown in fig. 3(e) and fig. 3(f) respectively. Response surface plot shows that on an increase in concentration of SDC (Edge activator) shows increase in deformability index as edge activator destabilize lipidic membrane and provides flexibility to vesicle. Increase in concentration of SPC shows slightly increase in deformability index but effect of SPC on deformability index is low as compared to SDC i.e. $\mathrm{X}_{2}$. The interaction of factors results in slightly increase then further decrease in deformability index.

Risk assessment was updated for formulation variables based on the results of the formulation development studies and an acceptable range for the high risk, formulation a variable has been established and was included in the control strategy.

\section{Selection of optimized batch}

$\mathrm{R}_{5}$ batch was selected as optimized batch as it showed optimum particle size $249.5 \pm 3.48$. Particle size required for flexisomes should be higher 3 to 4 times than that of skin pores, so they can squeeze themselves 3 to 4 times and can pass through narrow skin pores, optimum range selected for the particle size of flexisomes were (200 to $300 \mathrm{~nm}$ ) [7]. R5 showed maximum entrapment efficiency as $88.6 \pm 0.89$ and maximum deformability index as $31.75 \pm 0.98$.

\section{Evaluation of optimized batches}

Zeta potential measurements (surface charge study): The zeta potential value of the optimized EN-FS (R5) was found to be $(-22.5$ $\mathrm{mV}$ ) which shows a high negative surface charge on FSs which leads to high stability for the prepared formulation as it inhibits aggregation of vesicles due to negative charge, as shown in fig. 4 .

Surface morphology study by TEM: Flexisomes appeared as spherical and oval shape confirming the flexibility and vesicular characteristics, as shown in fig. 5. Two images of flexisomes as before filtration through extrusion membrane and after filtration through extrusion membrane shows that even passing through 100 nm diameter extrusion membrane flexisomes had maintained their spherical and oval shape confirming flexibility and vesicular characteristics. SDC (edge activator) plays important role that has a high radius of curvature that destabilize the lipid bilayers of vesicle, and increases vesicle flexibility. 


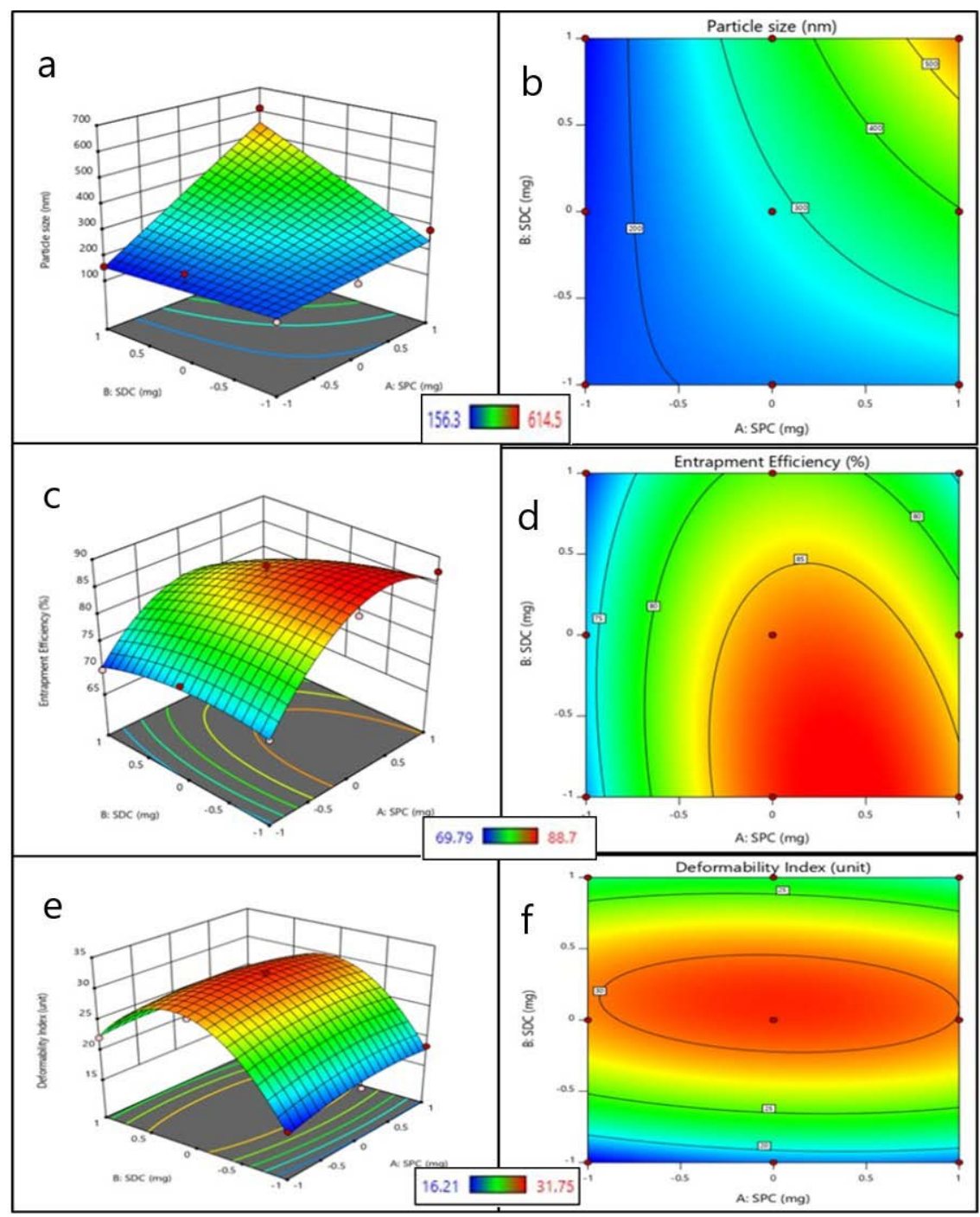

Fig. 3: (a): Response surface plot for particle size $\left(\mathrm{Y}_{1}\right)$. (b): Contour plot for particle size $\left(\mathrm{Y}_{1}\right)$. (c): Response surface plot for entrapment efficiency $\left(Y_{2}\right)(d)$ : Contour plot for entrapment efficiency $\left(Y_{2}\right)$. (e): Response surface plot for deformability index $\left(Y_{3}\right)$. ( $(f)$ : Contour plot for deformability index $\left(\mathrm{Y}_{3}\right)$

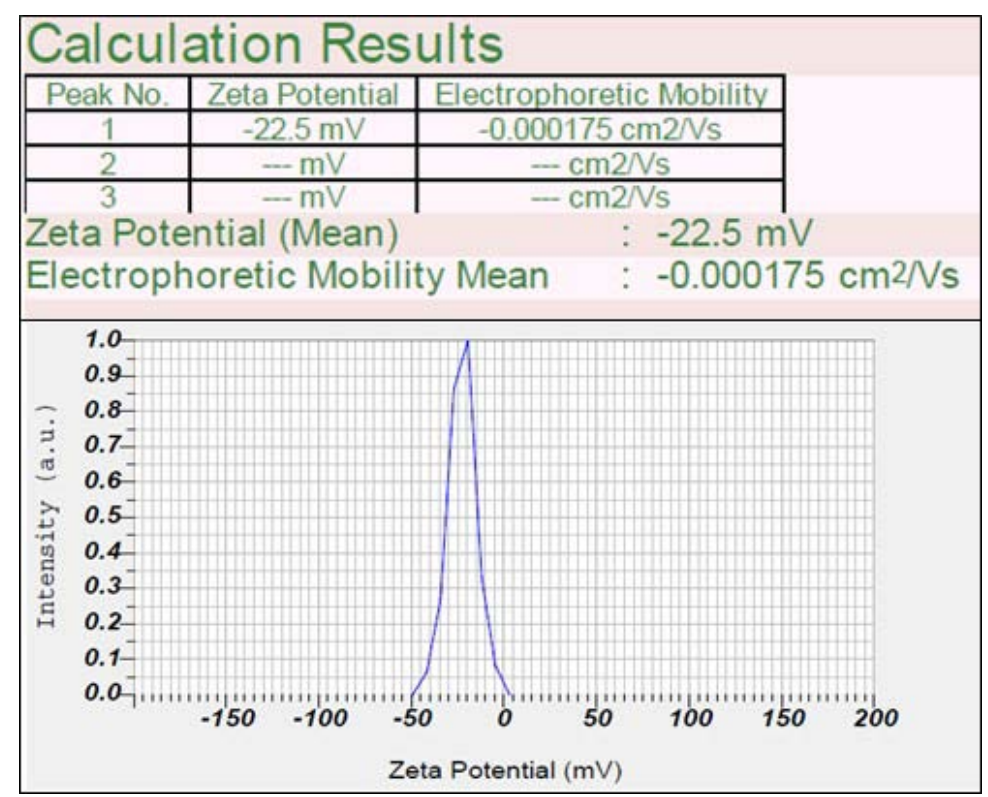

Fig. 4: Zeta potential of optimized batch (R5 batch) 


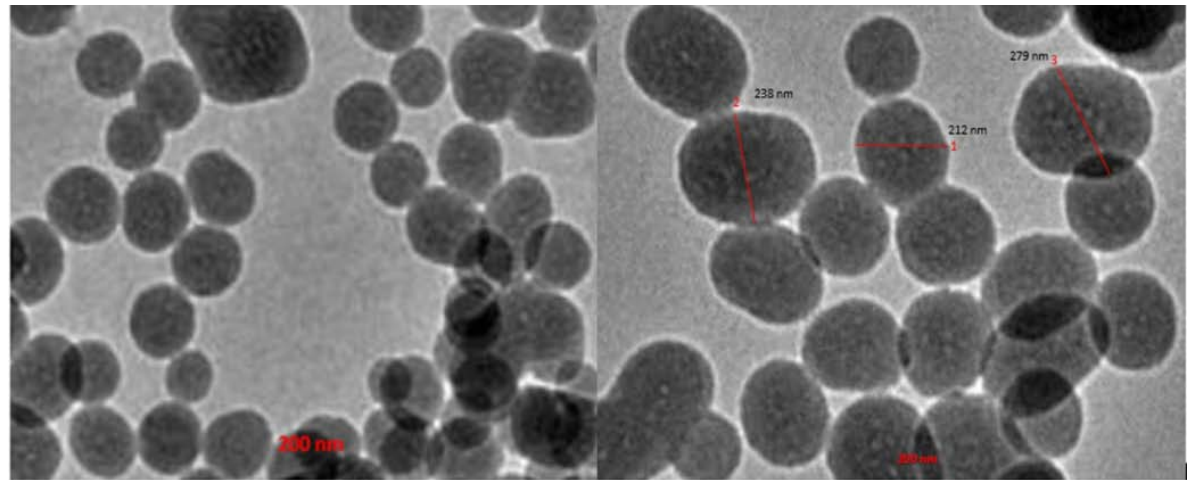

Fig. 5: TEM of econazole nitrate loaded flexisomes $\left(R_{5}\right)$ first before filtration through extrusion membrane second after filtration through extrusion membrane

\section{Evaluation of EN loaded FS gel}

EN-FS gel prepared was evaluated primarily on several factors as viscosity, spreadability, pH of gel and drug content. Gel showed optimum values of spreadability and viscosity at $3 \%$ concentration of Sepineo P600. Spreadability is an important property in the patient's point of view as good spreadability increases patient compliance, Spreadability found in range of 4 to $6 \mathrm{gm} / \mathrm{sec}$. which indicated good spreadability. Drug content was found in range of $93.2 \pm \%$ to $95.7 \pm \%$ which were in acceptable range. $\mathrm{pH}$ of flexisomal gel was found in range of $6.4 \pm$ to $6.8 \pm$ which was close to physiological $\mathrm{pH}$ of the skin. The viscosity of flexisomal gel should be in optimum range. Viscosity found 13400 centipoises [42].

\section{Ex vivo drug diffusion studies}

The ex vivo drug diffusion profiles of EN-FS hydrogel and plain EN hydrogel formulation are shown in fig. 6 . The percent drug diffusion at the end of $7 \mathrm{~h}$ was calculated. EN-FS hydrogel formulation showed considerably less skin permeation $(14.12 \pm \%)$ as compared to plain EN hydrogel formulation $(24.78 \pm \%)$ at the end of $7 \mathrm{~h}$. From the results of the permeation study found that the EN-FS hydrogel showed slow and controlled release rather than irregular release of plain EN hydrogel. Drug encapsulated in flexisomes reduces the variability and irregularity in drug release profile. Controlled drug diffusion was most effective in topical formulation as the more amount of drug will be available at site of action in epidermis and dermis layers, thus will avoid systemic adverse side effects and will release its content slowly and gradually over the period of time [43].

\section{Drug deposition studies on human cadaver skin}

EN-FS hydrogel showed higher drug retention in skin as compared to plain EN hydrogel, EN-FS showed skin retention of $78.36 \pm \%$ and plain EN gel showed $48.52 \pm \%$. As the more drug deposited in skin, then fungal infection treated more effectively in deep layers for a longer period of time. EN-FS gel is more efficient than plain EN hydrogel. As showed in fig. 7.

\section{Histopathological studies on human cadaver skin}

To check safety and irritancy of the skin after application of the gel, histopaths of human cadaver skin was taken and studied. Cadaver skin without treatment is used as control and EN-FS hydrogel treated cadaver skin is used as standard after $12 \mathrm{~h}$ of gel application. Histopaths are shown in fig. 8. Histopathology studies showed that no change in skin structure which shows safety of the formulation; there is no significant difference found in pathobiology of skin. After $12 \mathrm{~h}$ of application integrity of skin was maintained.

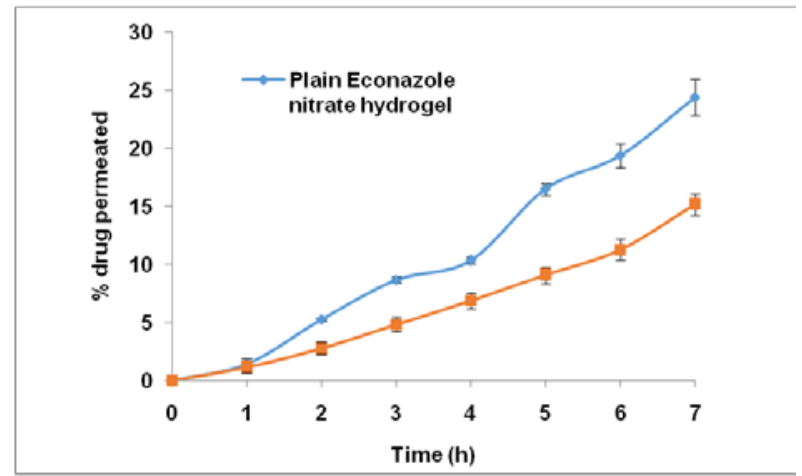

Fig. 6: Ex-vivo drug diffusion study of EN loaded TFs hydrogel and plain EN hydrogel through human cadaver skin, data are presented as mean $\pm S D(n=3)$

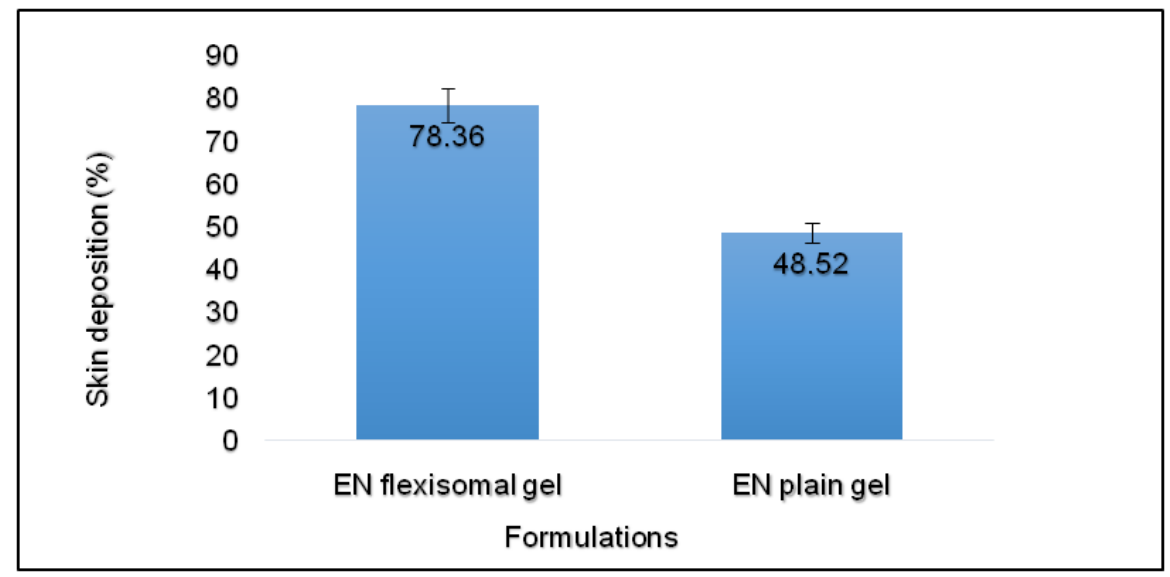

Fig. 7: Skin deposition of EN FS gel and plain EN gel, data are presented as mean $\pm \operatorname{SD}(n=3)$ 


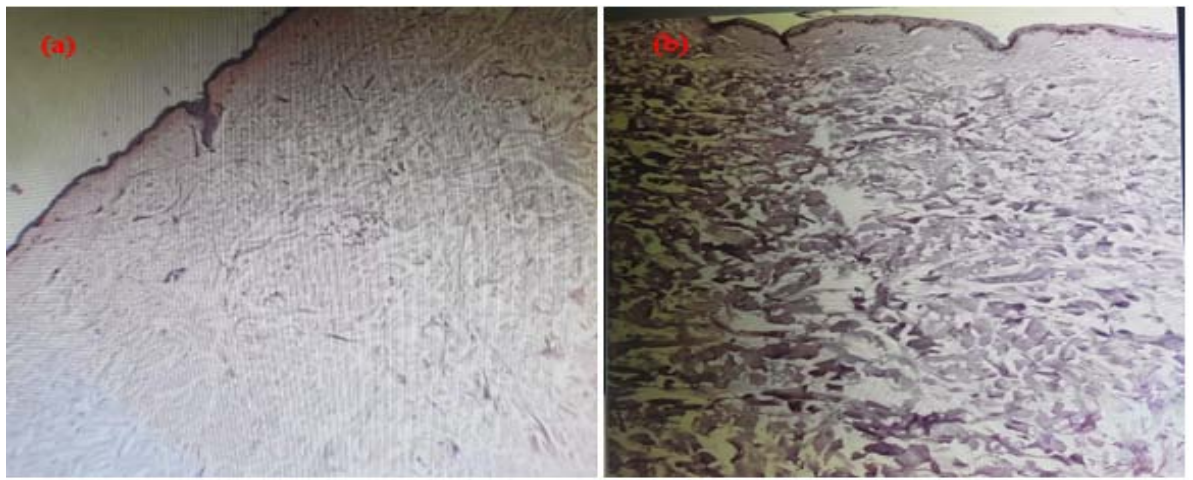

Fig. 8: Histopathological photographs of (a) Control skin (without treatment) (b) econazole nitrate loaded flexisomal sepineo gel treated skin

\section{Confocal laser scanning microscopy studies}

The confocal photomicrographs corresponding to various formulations as shown in fig. 9. applied onto the human cadaver skin show that the penetration from plain EN hydrogel was observed only to the uppermost layer of the skin (stratum corneum). In contrast, enhanced delivery of rhodamine red labelled EN-FS hydrogel in terms of depth and quantity was observed (i.e., as far as the fifth layer of epidermis, the stratum basale). It was found that Rhodamine red labelled EN-FS showed higher retention in the skin layer and deeper penetration, this is due to the flexibility of the flexisomes, they can deform and can penetrate through deeper skin layers. Thus can be used to effectively treat fungal infections occurred in deep layers of skin.

\section{In vitro antifungal activity study}

Developed EN-FS hydrogel formulation was found to be more effective in anti-fungal activity as compared to plain EN hydrogel as shown in fig. 10. The zone of inhibition EN-FS hydrogel against Candida albicans was $38 \mathrm{~mm}$ compared to $18 \mathrm{~mm}$ of plain econazole nitrate gel, indicating significantly higher efficacy of econazole nitrate loaded flexisomal sepineo gel formulation. it was found that the developed EN-FS hydrogel formulation was more effective than the plain EN hydrogel.

Design space was successfully established by using the design of experiment (DoE) tool. Fractional factorial design was used as screening design $\left(2^{5-2}\right)$. Total 8 batches were prepared by using five factors with two levels. Three factors were excluded and further study continued with 2 critical factors. Further full factorial design $\left(3^{2}\right)$ was used as optimization design by using 2 factors evaluated at 3 levels. Total 9 batches were prepared by using full factorial design, amongst 9 batches R5 batch was selected as optimized batch as it has optimum particle size, maximum entrapment efficiency and maximum deformability index.
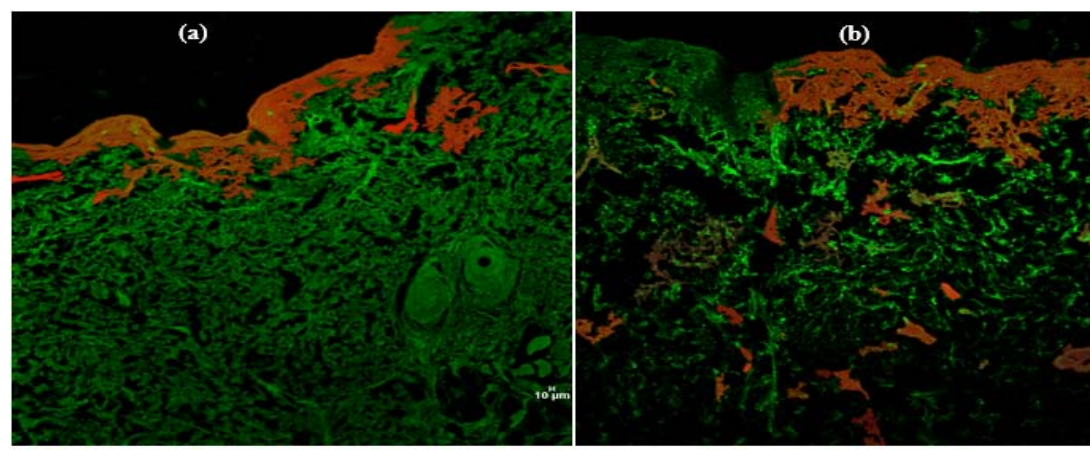

Fig. 9: CLSM images of (a) Plain econazole nitrate gel (b) Econazole nitrate loaded flexisomal gel showing deep penetration and retention in skin layers

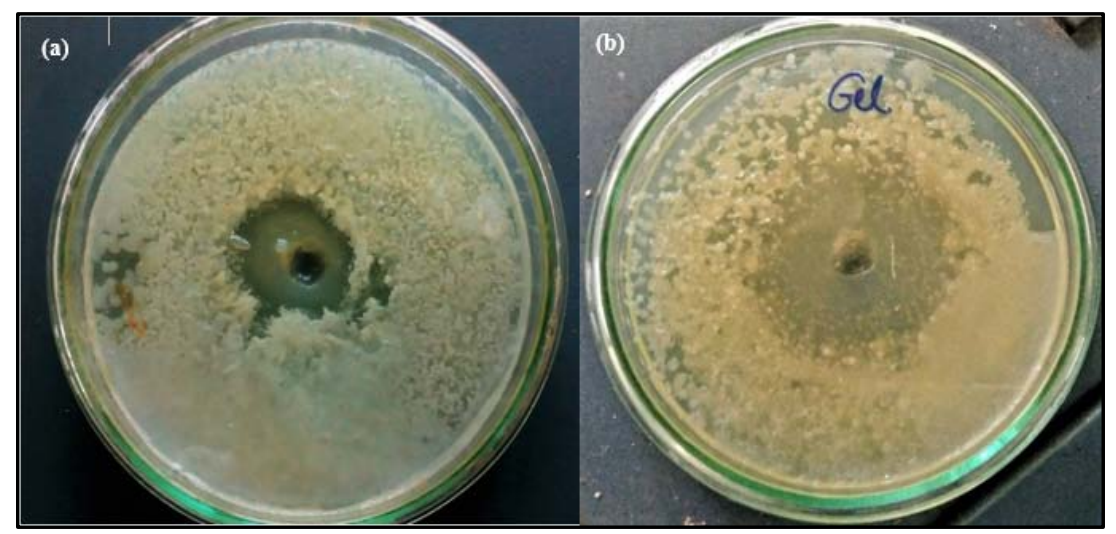

Fig. 10: In vitro antifungal activity of (a) plain econazole nitrate gel (b) econazole nitrate loaded flexisomal gel 
Table 5: Control strategy for econazole nitrate loaded flexisomal gel formulation

\begin{tabular}{|c|c|c|c|c|}
\hline Factor & $\begin{array}{l}\text { Attributes or } \\
\text { Parameters }\end{array}$ & $\begin{array}{l}\text { Range studied } \\
\text { (lab scale) }\end{array}$ & $\begin{array}{l}\text { Justification for } \\
\text { range }\end{array}$ & Purpose of control \\
\hline \multicolumn{5}{|c|}{ Critical material attributes } \\
\hline SPC conc. & $\begin{array}{l}\text { Lipid (Vesicle forming } \\
\text { agent) }\end{array}$ & $\begin{array}{l}250 \mathrm{mg} \text { to } 750 \\
\mathrm{mg}\end{array}$ & $\begin{array}{l}\text { Optimization range } \\
\text { studied }\end{array}$ & To ensure all flexisome's CQAs to meet consistently \\
\hline SDC conc. & Edge activator & $\begin{array}{l}50 \mathrm{mg} \text { to } 150 \\
\mathrm{mg}\end{array}$ & $\begin{array}{l}\text { Optimization range } \\
\text { studied }\end{array}$ & To ensure all flexisomes CQAs to meet consistently \\
\hline \multicolumn{5}{|c|}{ Critical process parameters } \\
\hline $\begin{array}{l}\text { Rotary } \\
\text { evaporation }\end{array}$ & Rotavap Speed & $\begin{array}{l}160 \mathrm{rpm} \text { to } \\
220 \mathrm{rpm}\end{array}$ & $\begin{array}{l}\text { Optimization range } \\
\text { studied }\end{array}$ & $\begin{array}{l}\text { To ensure complete evaporation of organic solvent and to } \\
\text { get thin uniform of lipidic vesicle. }\end{array}$ \\
\hline & Rotavap Temp. & $45^{\circ} \mathrm{C}$ to $60^{\circ} \mathrm{C}$ & & \\
\hline $\begin{array}{l}\text { Probe } \\
\text { sonication }\end{array}$ & Probe sonication time & $2 \mathrm{~min}$ to $4 \mathrm{~min}$ & $\begin{array}{l}\text { Optimization range } \\
\text { studied }\end{array}$ & To get desired nanosized vesicles. \\
\hline
\end{tabular}

\section{Control strategy}

A control strategy may include input material controls, process controls, and monitoring, design spaces around individual or multiple unit operations, and/or final product specifications used to ensure consistent quality. Control strategy for EN-FS is shown in table 5.

\section{CONCLUSION}

In this research work, EN-FS were successfully prepared and evaluated by implementing $\mathrm{QbD}$ approach using the conventional rotary evaporation sonication method. All three CQAs as particle size, deformability index and \% entrapment efficiency was highly dependent on the concentration of SPC and EA(SDC). Morphological study analyzed by TEM revealed the spherical size, shape of EN-FS. The optimized batch of flexisomes was further formulated into hydrogel. Skin permeation of EN-FS hydrogel was less but showed regular profile of drug rather than irregular profile of plain EN gel, drug deposition studies obtained revealed higher drug deposition in EN-FS than plain EN gel formulation so that more amount of drug will be available at site of action. Histological examination on cadaver skin indicated safety of EN-FS hydrogel integrity of the skin was maintained and there was no significant change in pathobiology of skin after application of formulation. In vitro antifungal studies indicated that the developed ENFS hydrogel formulation was more effective as compared to plain EN hydrogel. CLSM studies showed that EN-FS hydrogel showed good penetration properties as compared to plain EN hydrogel. From the above studies it was concluded that EN-FS shows high flexibility and enhanced antifungal activity and deeper penetration through skin layers thus they are found to be a potential carrier for drug deposition in skin layers without disturbing its integrity.

\section{AUTHORS CONTRIBUTIONS}

All the authors have contributed equally.

\section{CONFLICT OF INTERESTS}

The authors declare that they have no conflicts of interest

\section{REFERENCES}

1. Lawrence XY, Amidon G, Khan MA, Hoag SW, Polli J, Raju GK, et al. Understanding pharmaceutical quality by design. AAPS J 2014;16:771-83.

2. US Food and Drug Administration. Guidance for industry: Q8 (R2) pharmaceutical development. Center for Drug Evaluation and Research; 2009.

3. Patel H, Parmar S, Patel B. A comprehensive review on quality by design (QbD) in pharmaceuticals. Development 2013;4:5.

4. Guidance for industry: Q8 pharmaceutical development, US Department of Health and Human Service. FDA, Rockville MD; 2006. Available from: http://www.fda.gov/downloads/ RegulatoryInformation/Guidances/ucm12802.pdf. [Last accessed on 01 Jun 2013].

5. Guidance for industry: Q9 quality risk management, US Department of Health and Human Service FDA, Rockville MD; 2006. Available from: http://www.fda.gov/downloads/ Drugs/../Guidances/ucm073511.pdf [Last accessed on 1 Jun 2013].
6. Guideline IH. Pharmaceutical quality system q10. Current Step; 2008.

7. Mandlik SK, Siras SS, Birajdar KR. Optimization and characterization of sertaconazole nitrate flexisomes embedded in hydrogel for improved antifungal activity. J Liposome Res 2019;29:10-20.

8. Cevc G. Self-regulating smart carriers'for non-invasive and targeted drug delivery. Cell Mol Biol Lett 2002;7:224-5.

9. Patidar A, Thakur DS, Kumar P, Verma JH. A review on novel lipid-based nanocarriers. Int J Pharm Pharm Sci 2010;2:30-5.

10. Jain S, Jain P, Umamaheshwari RB, Jain NK. Transfersomes-a novel vesicular carrier for enhanced transdermal delivery: development, characterization, and performance evaluation. Drug Dev Ind Pharm 2003;29:1013-26.

11. El Zaafarany GM, Awad GA, Holayel SM, Mortada ND. Role of edge activators and surface charge in developing ultra deformable vesicles with enhanced skin delivery. Int J Pharm 2010;397:164-72.

12. Gupta PN, Mishra V, Singh P, Rawat A, Dubey P, Mahor S, et al. Tetanus toxoid-loaded transfersomes for topical immunization. J Pharm Pharmacol 2005;57:295-301.

13. Gungor S, Erdal MS, Aksu B. New formulation strategies in topical antifungal therapy. J Cosmet Dermatol Sci Appl 2013;3:56.

14. Keshri L, Pathak K. Development of thermodynamically stable nanostructured lipid carrier system using central composite design for zero-order permeation of econazole nitrate through epidermis. Pharm Dev Technol 2013;18:634-44.

15. Sharma R, Pathak K. Polymeric nanosponges as an alternative carrier for improved retention of econazole nitrate onto the skin through topical hydrogel formulation. Pharm Dev Technol 2011;16:367-76.

16. Panigrahi KC, Patra CN, Rao MB. Quality by design enabled development of oral self-nano emulsifying drug delivery system of a novel calcimimetic cinacalcet hcl using a porous carrier: in vitro and in vivo characterization. AAPS PharmSciTech. 2019;20:216.

17. Roy S. Quality by design: a holistic concept of building quality in pharmaceuticals. Int J Pharm Biomed Res 2012;3:100-8.

18. Tomba E, Facco P, Bezzo F, Barolo M. Latent variable modeling to assist the implementation of quality-by-design paradigms in pharmaceutical development and manufacturing: a review. Int J Pharm 2013;457:283-97.

19. Stamatis DH. Failure mode and effect analysis: FMEA from theory to execution. ASQ Quality Press; 2003.

20. Nasr M. Risk-based CMC review paradigm. In: Advisory committee for pharmaceutical science meeting; 2004.

21. Lawrence XY. Pharmaceutical quality by design: product and process development, understanding, and control. Pharm Res 2008;25:781-91.

22. Sonar G, Rawat S. Optimization of pantoprazole enteric pellets coating process by Qbd: effect of coating process variables on the intermediate quality of the product and scale-up. Int J Pharm Pharm Sci 2015;7:80-7.

23. Lionberger RA, Lee SL, Lee L, Raw A, Lawrence XY. Quality by design: concepts for ANDAs. AAPS J 2008;10:268-76.

24. Gupta A, Aggarwal G, Singla S, Arora R. Transfersomes: a novel vesicular carrier for enhanced transdermal delivery of 
sertraline: development, characterization, and performance evaluation. Sci Pharm 2012;80:1061-80.

25. Salama HA, Mahmoud AA, Kamel AO, Abdel Hady M, Awad GA Brain delivery of olanzapine by intranasal administration of transfersomal vesicles. J Liposome Res 2012;22:336-45.

26. Ahmed TA. Preparation of transfersomes encapsulating sildenafil aimed for transdermal drug delivery: plackettburman design and characterization. J Liposome Res 2015;25:1-10

27. Malakar J, Sen SO, Nayak AK, Sen KK. Formulation, optimization and evaluation of transferosomal gel for transdermal insulin delivery. Saudi Pharm J 2012;20:355-63.

28. Jain S, Tiwary AK, Sapra B, Jain NK. Formulation and evaluation of ethosomes for transdermal delivery of lamivudine. AAPS PharmSciTech 2007;8:249.

29. Gonzalez rodriguez ML, Arroyo CM, Cozar Bernal MJ, Gonzalez $\mathrm{R}$ PL, Leon JM, Calle M, et al. Deformability properties of timolol-loaded transfersomes based on the extrusion mechanism. Statistical optimization of the process. Drug Development Industrial Pharm 2016;42:1683-94.

30. Mandlik SK, Nandare DS, Joshi MM, Chudiwal PD, Jain KS. Statistical optimization of orodispersible tablets containing telmisartan using factorial design and response surface methodology. Res J Pharm Technol 2009;2:548-51.

31. Joshi SA, Chavhan SS, Sawant KK. Rivastigmine-loaded PLGA and PBCA nanoparticles: preparation, optimization, characterization, in vitro and pharmacodynamic studies. Eur J Pharm Biopharm 2010;76:189-99.

32. Bonacucina G, Cespi M, Palmieri GF. Characterization and stability of emulsion gels based on acrylamide/sodium acryloyldimethyl taurate copolymer. AAPS PharmSciTech 2009;10:368-75.

33. Zheng WS, Fang XQ, Wang LL, Zhang YJ. Preparation and quality assessment of itraconazole transfersomes. Int J Pharm 2012;436:291-8.
34. Janardhan PP, Praveen CS, Vasant GS. Evaluation of wound healing activity of silver sulfadiazine emulgel $(1 \%)$ in the rat burn wound model and its skin irritation study. Indian Drugs 2012;49:40-3.

35. Bikkad ML, Nathani AH, Mandlik SK, Shrotriya SN, Ranpise NS. Halobetasol propionate-loaded solid lipid nanoparticles (SLN) for skin targeting by topical delivery. J Liposome Res 2014;24:113-23.

36. Sahoo S, Pani NR, Sahoo SK. Effect of microemulsion in topical sertaconazole hydrogel: in vitro and in vivo study. Drug Delivery 2016;23:338-45.

37. Kusuma SA, Abdassah M, Valas BE. Formulation and evaluation of anti-acne gel containing citrus aurantifolia fruit juice using carbopol as gelling agent. Int J Appl Pharm 2018;10:147-52.

38. Hussain A, Samad A, Singh SK, Ahsan MN, Haque MW, Faruk A, et al. Nanoemulsion gel-based topical delivery of an antifungal drug: in vitro activity and in vivo evaluation. Drug Delivery 2016;23:642-57.

39. Verma P, Pathak K. Nanosized ethanolic vesicles loaded with econazole nitrate for the treatment of deep fungal infections through topical gel formulation. Nanomed: Nanotechnol Biol Med 2012;8:489-96.

40. Subongkot T, Wonglertnirant N, Songprakhon P, Rojanarata T, Opanasopit P, Ngawhirunpat T. Visualization of ultradeformable liposomes penetration pathways and their skin interaction by confocal laser scanning microscopy. Int J Pharm 2013;441:151-61.

41. Nayak A, Laha B, Sen K. Development of hydroxyapatiteciprofloxacin bone-implants using» Quality by design «. Acta Pharm 2011;61:25-36.

42. Shreya AB, Managuli RS, Menon J, Kondapalli L, Hegde AR, Avadhani $\mathrm{K}$, et al. Nano-transfersomal formulations for transdermal delivery of asenapine maleate: in vitro and in vivo performance evaluations. J Liposome Res 2016;26:221-32.

43. Pople PV, Singh KK. Development and evaluation of a topical formulation containing solid lipid nanoparticles of vitamin A. AAPS PharmSciTech 2006; 7:E63-9. 